\title{
Analysis of The Problems Existing in Network Live Broadcast
}

\author{
Zhengxiang WANG ${ }^{1}$ \\ ${ }^{1}$ School of Business Administration Baise University, Baise, Guangxi)
}

\begin{abstract}
Internet live broadcast marketing (LBM) is an important form of product exchange in the era of post Covid-2019, and it is the fifth revolution of retail industry characterized by "new retail". From the process of evolution and development of webcast, this paper systematically analyzes the characteristics of LBM with empirical research methods, as well as imbalance of the input and output of LBM, the "high income but low ability" of the anchors, and suspected false propaganda. This paper is aimed to analyze the specific cases from the perspective of "people, goods and markets" in terms of the unique laws of retail industry, using the traditional "4P" theory of marketing management and the new thinking of marketing 4.0 in the digital era, and to put forward specific suggestions. Meanwhile, this paper will start from the status quo of the most important core element of LBM - anchor talent, and suggests some specific training programs for the improvement of the anchor talent. Based on McKinsey's China Research Report, this study also analyzes the trend from global supply-chain to regional evolution in the era of post Covid-2019, especially the characteristics of gradually increasing trade interdependence between Southeast Asian countries. It is suggested that colleges and universities should speed up the cultivation of interdisciplinary anchor talents with both "bilingual" skills and marketing knowledge, to promote the development of LBM in Southeast Asian countries. Finally, this study gives specific suggestions on the establishment and improvement of laws and regulations in the live broadcast economy, to call on the attention of the government agencies, and lead the live broadcast economy to the track of sustainable development.
\end{abstract}

\section{Decades of retail growth ended with the COVID-19.}

This is a common dilemma for offline retail enterprises. The "big data thermal map" released by Cheetah Mobile shows that the customer flow of supermarkets in China has declined seriously, and the average daily shopping mall has dropped by more than $60 \%$. After the closure of Wuhan on January 23, the customer flow of shopping malls in each city dropped sharply, with a single day drop of more than $45 \%$. ${ }^{[1]}$

Physical stores are the main source of income for all retail enterprises. Under the impact of the COVID-19, they have lost the most direct contact with consumers. Every offline retail business, whether it is the beauty industry, or catering, clothing retail, supermarket, has suffered a decline due to the lack of customer flow.

However, this does not mean that the demand of consumers disappears, and their consumer behavior has been changed due to the isolation at home. For the traditional retail industry, it is both a crisis and an opportunity.

The black swan, COVID-19, has changed consumer behavior, however, the new consumer behavior has forced supply-side development.

As a result, live broadcast marketing (LBM) is like a "fire in winter" that has burned all over China. From the famous celebrities of the live internet, to government officials at all levels, from CEOs of enterprises to shopping guides of shopping centers, many figures have joined the ranks of LBM, which has become a marketing phenomenon with Chinese characteristics.

\section{A review of marketing theory of live broadcasting}

2016 was the first year of live webcast in China. Although e-commerce was born in the United States in 1995 , China is the only country with rapid changes and development.

With the high popularity of mobile Internet, China's e-commerce has changed from "retail e-commerce" in 2008 to social e-commerce later and social content e-commerce nowadays. In 2019, online sales in China has grown by $30 \%$, reaching nearly $\$ 2$ trillion, accounting for more than $50 \%$ of the global online sales, while online sales in the U.S. A. is about $\$ 600$ billion. ${ }^{22}{ }^{2}$

In the period of commercial transformation, LBM is a kind of social content e-commerce. The basic principles are as follows:

LBM refers to the vertical integration of retail supply chain and profit chain. The production, branding and distribution of products are all completed by brands.

In this way, products can be delivered directly from the factory to the consumer. Many new "digital native vertical brands" compete for quality at a lower cost and 
take price transparency as a part of customer perceived value. With vertical integration, delivery time is shorter, return and replacement are more convenient, and consumers can obtain more information about products and inventory. ${ }^{[3]}$

2. LBM eliminates intermediaries and releases more discount to consumers. Not only that, it also helps consumers reduce time cost, search cost and spiritual cost, but also greatly improves consumers' perceived value and obtains consumer surplus.

Therefore, internet LBM is regarded as the fifth revolution of retail industry, which is the revolution of "celebrity paradigm" after "platform paradigm" and "algorithm paradigm".

\section{Practice of LBM}

LBM is popular among the public because of its visible products, easy access to product knowledge, the lower price of the whole internet, and zero distance interaction with online anchors.

LBM reconstructs the relationship of "people", "goods" and "market", making it a "standard configuration" for e-commerce, brands and businesses. With the rapid increase of its penetration rate, especially the increase of uncertain factors in the era of post Covid-2019, LBM has become the main way for many industries, especially the retail industry, to resume operation.

According to the research report, the total transaction volume of the e-commerce alliance is expected to exceed 300 billion yuan soon. ${ }^{[4]}$

Therefore, with this phenomenon, it is very common for internet anchors like Weiya, Li Jiaqi and Simba to sell more than 100 million yuan in a live broadcast.

The CEO of Gree, Dong Mingzhu's sales of a live broadcast on June 18 reached 6.54 billion yuan, and the daily sales accounted for $32 \%$ of the first quarter's sales.

All in all, the participation of film and television celebrities, intellectual businessmen and owners of small and medium-sized enterprises has promoted the rapid development of LBM.

\section{Analysis on the imbalance of the input and output of LBM}

According to the Research Report of Shenwan Hongyuan, the number of live e-commerce users in 2019 reached 265 million, with a scale of about 400 billion yuans, accounting for $4.7 \%$ of the online retail sales of physical goods, the penetration rate has been greatly improved. Among them, the Gmv of Taobao live e-commerce in 2019 was 200 billion yuans, accounting for half of the market share. ${ }^{[5]}$

In 2020, the scale of live e-commerce market is expected to reach 1 trillion yuan, and the penetration rate will rise to $9.8 \%$.

LBM has attracted many people's attention because of the good market performance and broad market prospects.

Due to the entertainment property of LBM and the dormancy of film and television celebrities during the Covid-2019, many film and television celebrities have found their own roles in LBM even they lack basic knowledge of marketing communication.

However, in addition to increasing the bubble of LBM, they seized a huge amount of endorsement fees, while leaving the tears of the brand owners behind.

Xiao Shenyang, who has more than 17.4 million Weibo fans and over 19 million TIKTOK fans, sold liquor on the live broadcast, orders more than 20 orders, 16 replacement in second day. Ye Yixi sold tea sets lively, with a customer price of more than 200 yuan, and nearly 900000 online viewers, only selling less than 2000 yuan.

Li Xiang, A-lister celebrity, sold mink coats, and the same result was achieved. After a live broadcast, not even a mink coat sold, but Li Xiang's endorsement fee was 0.8 million yuan.

From a professional point of view, this is a mistake in the selection. Mink coat is a category that has no selling point to attract users. On the other hand, before the live broadcast, there was not enough homework on pricing strategy, and there was no clear character design for high-end clothing. Even though Weiya, who has a lot of experience, conducted LBM of mink coat, the return rate is as high as $60 \%$. As a "newcomer" of LBM, Li Xiang's failure is expected.

Chen he's failure is more dramatic. Crayfish is the easiest product to sell. At the beginning, Chen he's live broadcast also achieved very good results, and the fans enjoyed it very much. When the fans are still immersed in the delicacy of crayfish, when the camera turns, Chen he talks about the toilet cover. The 180-degree turning of the style makes the fans lose half of the time.

In addition, some products in celebrity LBM have quality problems, and some celebrities hide to avoid accountability.

Zhang Shaohan recommended a sunscreen spray to fans on a live broadcast. After she just finished saying that the spray was good for her own testing, the company that had been punched out the spray was punished by the administration, and the production license of skin care products was revoked. The studio was filled with embarrassment.

$\mathrm{Wu}$ Xiaobo, an intellectual businessman, sold only 15 cans of milk powder after a live broadcast. Therefore, he was sardonically referred as "Wu 15 cans".

The widespread phenomenon of "high salary and low efficiency" of the above film and television celebrities proves, on the other hand, that LBM is not only entertainment, but also extremely important professional support. The so-called professionalism requires the anchor to have solid marketing management theory and rich practical experience.

And many anchors, including not limited to film and television celebrities, are under-qualified.

A qualified anchor should have the knowledge of "4P" in marketing management, that is, product, pricing, channel, promotion, and grasp the essence of "new 4P", that is, the specific application of "personnel, program, process and performance". [6]

The most basic is, the anchor also needs to have the superb "speech skill", namely the communication ability 
with the customers.

In this way, the portrait of a qualified anchor can be clearly described:

A qualified anchor should be very familiar with the product, and can accurately find out the selling point of the product, negotiate price with the brand from the user's point of view, truly realize the "lowest price of the whole internet" expected by users, have strong communication ability with users, and have kind of the art. The most important thing is a complete set of solutions and processes before live broadcast, including drainage, promotion, catalysis, entertainment, interaction, etc.

And all these are what government officials anchor, film and television celebrity anchor do not have.

Because of the existence of these unqualified anchors, they cannot control a live broadcast, at the same time, the high "endorsement fee" is also charged without hesitation. If it goes on like this, it will only lead the LBM, which is the last mode of content marketing, into darkness. It will not only result in the imbalance between the input and output of LBM, but also bring about the situation of low efficiency of social resources.

\section{The core elements of live broadcast economy}

Harold Innis, a Canadian political economist, said in his book The Bias of Communication that the emergence of a new medium will lead to the emergence of a new civilization. ${ }^{[7]}$

COVID-19 is a "black swan", to some extent, it has seriously damaged the real economy and objectively changed the current situation of retail industry. But it also promoted the explosive growth of LBM.

The broadcasting platform provides the necessary foundation for the rise of live broadcasting economy. Nowadays, there are more than 100 kinds of live app and live related applications, which provide a convenient and fast live platform for the public. It has greatly accelerated the development of live broadcast economy.

In LBM, live broadcast is the form, the anchor is the media, the content is the means, and the product exchange is the core. However, anchors rely on fans, fans rely on IP. Anchors with distinct personality and matching people, goods and markets have high fan stickiness and high commercial conversion rate. The same is the LBM. In the actual operation, some rely on the anchor + product, and some rely on the brand product + celebrity. Therefore, there are two different development paths, the former is relying on "big celebrity", the latter "product".

The former relies on personal charm and advocates the "fans effect" of celebrities, which is a kind of "personal heroism" to some extent; the latter relies on the influence of brand to win by resonance between brand and consumers. Of course, it also depends on the timely adjustment of other factors and modes in operation.

\subsection{The status quo of Internet Celebrity in LBM}

Nowadays, at least 11 places in China, including Guangzhou, Sichuan, Shanghai, Chongqing, Heze, Jinan, Qingdao, Beijing, Quanzhou, Hangzhou and Yiwu, have issued special policies to support the development of Taobao live broadcasting industry in terms of policy support, entrepreneurship award, talent introduction, tax incentives, rent reduction and industry alliance. Guangzhou proposed "building a live e-commerce city", Sichuan issued the first provincial live broadcasting industry development plan in China, and Shanghai released the "plan for promoting online new economic development", Chongqing proposed "cultivating 10000 LBM talents", and Qingdao proposed "building a leading city of live broadcasting e-commerce in northern China", Beijing proposed "promoting physical commerce to promote live broadcast sales", and Quanzhou funded the establishment of live broadcasting base, Hangzhou "live e-commerce talents can be recognized as class B talents", Yiwu proposed "strive to achieve the grand goal of exceeding 100 billion yuan of live e-commerce transaction volume in 2022.

Li Jiaqi, one of the "online celebrities", was introduced by Chongming District of Shanghai as the first batch of special talents in 2020. Due to her outstanding contribution in helping agriculture and poverty alleviation, Weiya was added by Yunnan Youth Federation as a standing committee member and Promotion Ambassador of Yunnan Communist Youth League.

\subsection{The way of anchor cultivation in LBM}

At present, there are about 100000 Internet Celebrities nationwide, which is far from enough for an industry with a market scale of more than one trillion yuan. The lack of "Middle- anchor" will seriously restrict the healthy development of live broadcast economy.

Therefore, it is necessary to speed up the cultivation of "Middle-anchor" through multiple channels and means.

The so-called Middle-anchor is another name for the Middle of the long tail in Anderson's "long tail theory". ${ }^{[8]}$ Specifically speaking, the Middle-anchor's fans range from more than 100000 to millions. Although the influence is far less than that of the head anchor, their fans have distinct personality, and marketing is more adaptable. Therefore, they should be the main force of the live broadcast economy.

Therefore, it is suggested that the national finance and economics colleges and application-oriented vocational colleges should meet the market demand for talents in the circulation industry and set up a major department of webcast anchor.

Especially since 2019, the global value chain has shown a trend of strengthening regionalization and weakening globalization. This situation is particularly significant in Asia, for example, Malaysia, Singapore and the Philippines, whose largest trading partner is China. Some of these economies are equally dependent on Chinese capital. For example, in 2013-2017, Malaysia's 
FDI from China was equivalent to $6 \%$ of its total domestic investment; in Singapore, it was 5\%. [9]

Therefore, it is very important to cultivate bilingual anchors and use new forms of trade circulation. Particularly, it is very urgent for an anchor to have the language advantages of Korean, Thai, Malay and other foreign languages, as well as a solid marketing knowledge.

When the related enterprises, especially the retail industry, recruit management trainees, they should also bring the webcast anchor into the training direction.

To adapt to the changes of the retail industry pattern in the post Covid-2019 era, the online LBM of shopping centers and department stores will come to be normal. Their shopping guides are familiar with products, have a certain amount of private flow, and have certain customer relationship management skills, so they also have the potential of "Middle-anchor". Therefore, improving the targeted training for these people is a good way to strengthen the Middle-anchor.

\section{Laws and regulations needed in live broadcast economy}

As a new marketing method, the related rules and regulations of LBM are not perfect. Therefore, it is very important to establish and improve the laws and regulations to escort the live broadcast economy.

The government agencies should establish the internet market supervision as soon as possible, and at the same time, it should supplement specific cases and punishment methods to the Code of Conduct of Online LBM Activities, to maintain the sound market order of live broadcast.

It is necessary to crack down on false propaganda activities suspected of violating the Advertising Law such as "the lowest price of the whole internet". Especially for large-scale LBM, the price reporting and checking system in advance should be implemented. If any false pricing behavior is found, punishment should be resolutely imposed, to effectively protect the rights and interests of consumers from infringement.

A regulation method should be formulated linking the sales volume to the endorsement fee, space occupying fee and commission of the anchor, to effectively protect the interests of manufacturers and brand owners, meanwhile, to curb the emergence of LBM bubble.

If there is a serious "rollover" phenomenon in the LBM, the anchor should bear the civil compensation liability and even criminal legal liability, so as to solve the abnormal and unfair phenomenon of the anchor "bearing the profit but not the loss".

Nowadays, the Code of Conduct for Online LBM Activities has been formally implemented, however, whether it can become a good medicine to cure the stubborn diseases of the industry and end the wild growing chaos, requires the close cooperation of relevant stakeholders and the supervision role of the news media, and more importantly, the seller and the anchor of the live broadcast need to be self-disciplined and regulate their own behavior.
Only under the restriction of laws and regulations, the supervision of news media, and the self-restraint and standardization of the marketing side of live broadcasting, can the live broadcasting economy embark on the fast track of sustainable development.

\section{References}

1. https://tech.sina.com.cn/roll/2020-02-23/doc-iimxyq vz5104694.shtml

2. https://new.qq.com/omn/20190408/20190408A0KH N7.html

3. Barbara E. Kahn, The Shopping Revolution: How Successful Retailers Win Customers in an Era of Endless Disruption. Wharton Digital Press, 2018

4. http://www.cs.com.cn/cj2020/202004/t20200408_60 42904.html

5. https://t.cj.sina.com.cn/articles/view/5572912412/14 c2be51c01900r7dj?from=tech

6. Kotler, Philip and Keller Kelvin Lane. Marketing Management. (15th Global Edition) Edinburgh: Pearson Education. 2016

7. Innis, Harold Adams. The Bias of Communication. University of Toronto Press. 1964

8. Anderson, Chris. The Long Tail: Why the Future of Business Is Selling Less of More. Hachette Books. 2006

9. McKinsey China report 2019 (full version) (In Chinese)

https://www.sohu.com/a/361554518_468675 